\title{
Fetal Mummification in Doe along with Live Fetus: A Rare Case Study
}

\author{
Dushyant Yadav ${ }^{1,2} *$, Rupali Rautela ${ }^{2}$, A.R. Mustapha ${ }^{3,4}$, Deepesh Gautam ${ }^{4}$, \\ Brijesh Kumar $^{1}$, G.K. Das ${ }^{1}$, K. Narayanan ${ }^{1}$, S.K. Singh ${ }^{1}$ and Harendra Kumar ${ }^{1}$ \\ ${ }^{1}$ Veterinary Gynaecology and Obstetrics, Division of Animal Reproduction, \\ IVRI, Izatnagar, Bareilly, India \\ ${ }^{2}$ FVAS, Banaras Hindu University, India \\ ${ }^{3}$ Division of Animal Reproduction, ${ }^{4}$ Division of Surgery, IVRI, Izatnagar, Bareilly, India \\ ${ }^{4}$ Department of Theriogenology, Faculty of Veterinary Medicine, University of Maiduguri, \\ Borno State, Nigeria
}

*Corresponding author

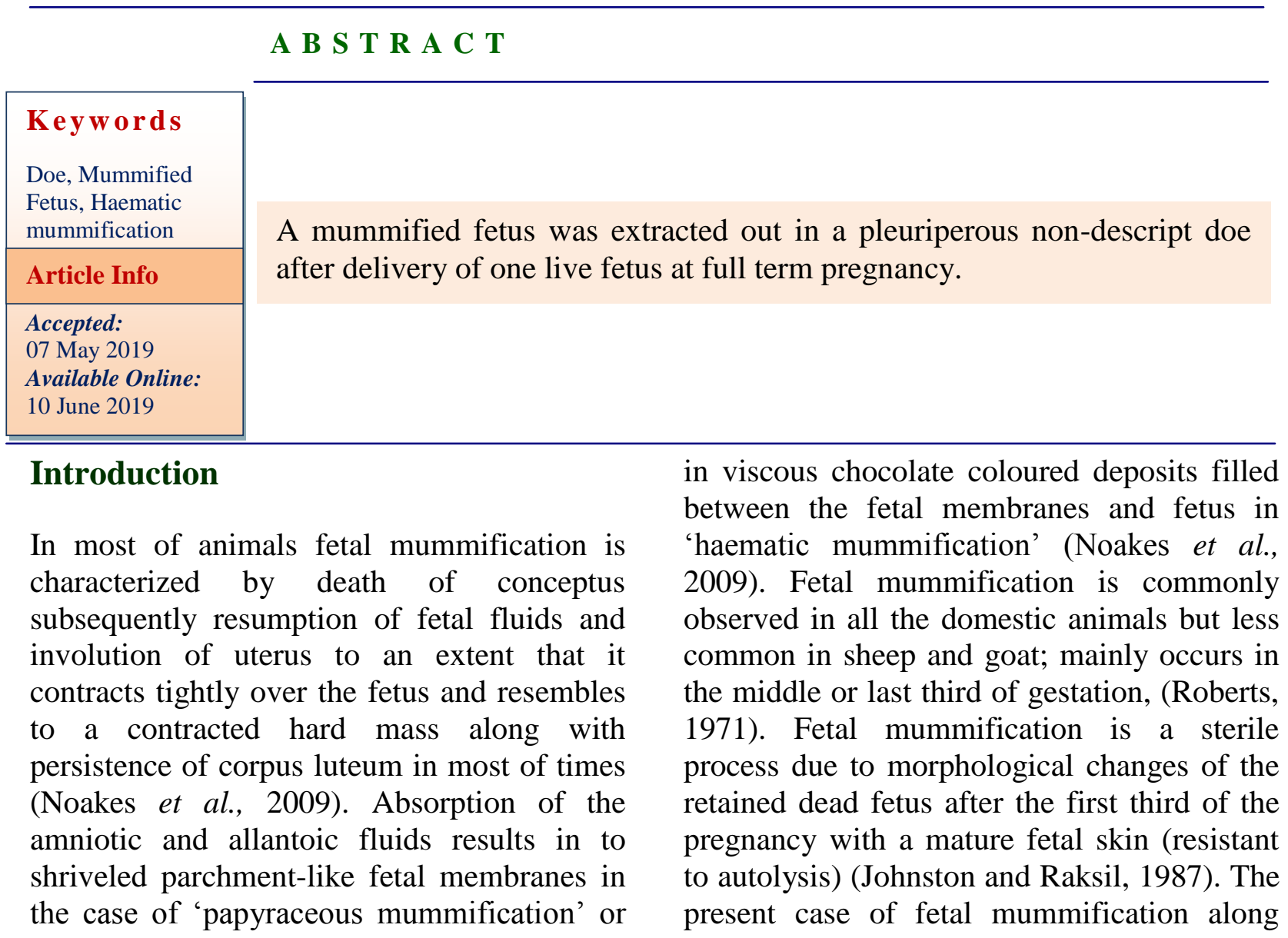


with delivery of one live fetus at the term is placed on record.

\section{Case history and clinical examination}

A non-descript doe of about 2 year age on her $2^{\text {nd }}$ parity brought to the Referral Veterinary Polyclinic, IVRI with a clinical history of full term gestation and delivery of one live fetus before 12 hours of presentation; as said by owner a small mass along with a membranous covering lodged into the vagina of dam just after the delivery of first fetus with continuous abdominal straining. Feed and water intake of animal were slightly reduced. In the previous parturition no such complication was observed and fetuses were delivered without any manual assistance.

\section{Clinical examination}

Clinical examinations revealed that a small hard mass was lodged in the dam's vagina which was also visible externally.
On per-vaginal examination (digitally) a hard mass with bony texture was felt with a membranous covering along with viscous chocolate color fluid filled.

\section{Treatment and Discussion}

After giving gentle traction with lubricated hand a contracted hard mass (mummified fetus) covered in slightly shriveled membranous structure (fetal membrane) along with chocolate colored viscous fluid, extracted out per-vaginally (Fig. 1 \& 2).

Thorough examination of extracted hard mass was confirmed as mummified fetus in which all the parts of fetus were present in a contracted form.

The doe was uneventfully recovered after supportive therapy.

Fig.1\&2

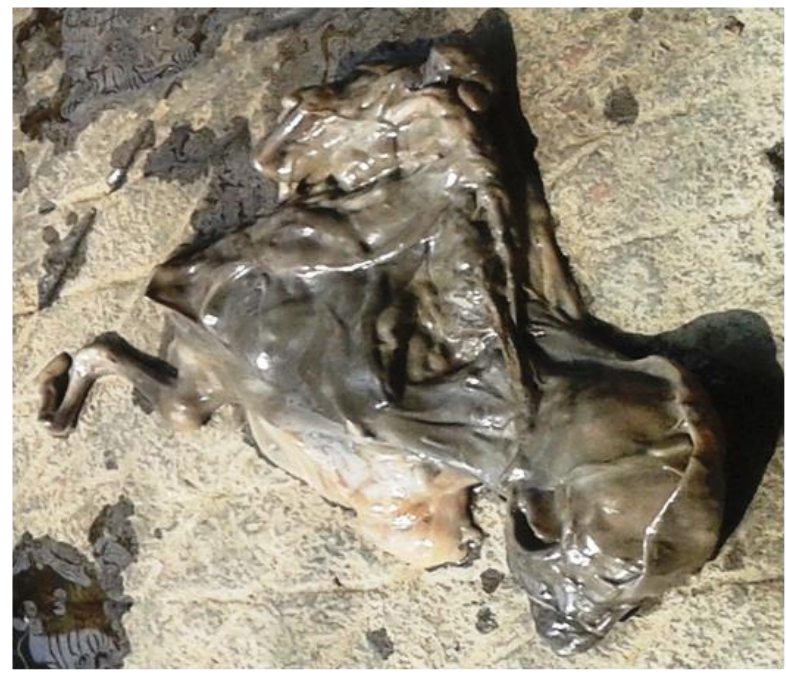

Fig :1

Mummified fetus after two month postpartum and also at the time of complete gestation following caesarean section have been

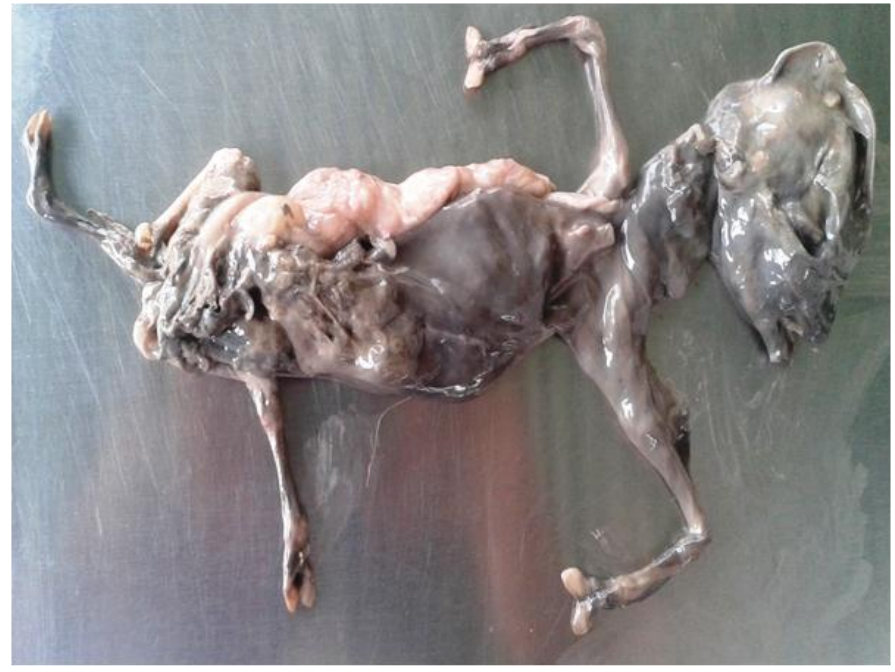

Fig :2

reported by Tutt (1997), Bhardwaj and Kumar (2014) and Ogbu et al., (2011). In our case mummified fetus was observed at the time of 
kidding along with one live fetus. Fetal mummification appears to be more common in twin pregnancies in the goats than singletons and carried upto the term (Ogbu et $a l ., 2011)$ as observed in present case. The present case is a type of 'haematic mummifiaction' and rare of its kind due to one normal live fetus along with mummified fetus at full term gestation was delivered pervaginally.

\section{References}

Bhardwaj, R. K., and Kumar Sudhir. 2014. Management of goat with one mummified and live fetus. The Indian Veterinary Journal, 91(02): 64-65

Johnston, S. D. and S. Raksil. 1987. Veterinary Clinics of North America. Fetal loss in the dog and cat: Small
Animal Practice. 4: Elsevier publishing, USA.

Noakes, D. E., Parkinson T. J. and England G. C. W. 2009. Veterinary Reproduction and Obstetrics, WB Saunders Company Ltd., London, 9th edition.

Ogbu, E. O., Omamegbe J.O., Ukaha R., Njoku, U.N., Nnakwe, K. and Nwoha, R.I.O. 2011. Dystocia and foetal mummification in a West African dwarf doe (A case report). Nigerian Veterinary Journal, 32(4): 357- 361.

Roberts, S. J., 1971. Veterinary Obstetrics and Genital Diseases CBS Publishers and Distributors, Delhi, India, 2nd edition.

Tutt C. L. C. 1997. Postpartum mummification of a co-twin fetus in a Cameroon dwarf doe. Veterinary Records, 140: 229-231.

\section{How to cite this article:}

Dushyant Yadav, Rupali Rautela, A.R. Mustapha, Deepesh Gautam, Brijesh Kumar, G.K. Das, K. Narayanan, S.K. Singh and Harendra Kumar. 2019. Fetal Mummification in Doe along with Live Fetus: A Rare Case Study. Int.J.Curr.Microbiol.App.Sci. 8(06): 784-786. doi: https://doi.org/10.20546/ijcmas.2019.806.094 